\title{
Metal-binding particles enhance germination and radicle tolerance index of the metallophyte grass Astrebla lappacea Lindl. under phytotoxic lead and zinc conditions
}

\author{
L. Rossato Centre for Mined Land Rehabilitation, The University of Queensland, Australia
}

A. Pudmenzky Centre for Mined Land Rehabilitation, The University of Queensland, Australia

D. Doley Centre for Mined Land Rehabilitation, The University of Queensland, Australia

M. Monteiro Australian Institute for Bioengineering and Nanotechnology, The University of Queensland, Australia

M. Whittaker Centre for Advanced Macromolecular Design, The University of New South Wales, Australia

S. Schmidt School of Biological Sciences, The University of Queensland, Australia

J. MacFarlane Centre for Mined Land Rehabilitation, The University of Queensland, Australia

A.J.M. Baker School of Botany, The University of Melbourne; and Environmental Earth Sciences International Pty Ltd, Australia

\begin{abstract}
Metal-contaminated soils often lack effective vegetation cover and are consequently prone to disturbance and in some cases leaching. The establishment of self-sustaining plant cover on contaminated sites often requires a reduction in available metal concentrations in the rooting zone. In theory, hydrogel particles have the potential to improve plant establishment rates and site rehabilitation by: (i) detoxifying the soils in terms of heavy metal 'capture' and providing a source of water for plants during germination and establishment; (ii) allowing the establishment of selected metal tolerant plants (metallophytes) at high soil metal concentrations and under drought; and (iii) by acting in synergy with the sequestration of metals by metallophytes, to achieve phytostabilisation of contaminated sites and reduce the risks of uncontrolled metal transfers into the environment via wind and water erosion.

Various micron- and nano-sized metal-binding cross-linked acrylamide polymer hydrogel particles were synthesised and tested in laboratory-scale experiments in order to determine: (i) the capacity of particles to sequester heavy metals (lead (Pb), zinc ( $\mathrm{Zn})$, copper ( $\mathrm{Cu}$ ) and the metalloid arsenic (As)) in solution at high soluble concentrations; (ii) the water-holding capacity of the particles; and (iii) the effect of particle treatment on the in vitro germination percentage and radicle tolerance index (RTI at 2 days) of an Australian metallophyte grass (Astrebla lappacea Lindl.) in the presence of high solution concentrations of heavy metals normally phytotoxic to that species.

The results show that one micron-sized thiol functional cross-linked acrylamide polymer hydrogel (X3) significantly reduced the available solution concentrations of $\mathrm{Pb}(9,650 \mu \mathrm{M}), \mathrm{Cu}(4,000 \mu \mathrm{M})$ and Zn $(10,000 \mu M)$ by $86.5 \%, 75.5 \%$ and $63.8 \%$ respectively. Arsenic $(667 \mu M)$ was excluded from the polymer network. This polymer could hold deionised water up to 607.8\% (6.1 times) of its dry mass. Alone, it enhanced seed germination, and at otherwise phytotoxic $\mathrm{Pb}(9,650 \mu \mathrm{M})$ and $\mathrm{Zn}(10,000 \mu \mathrm{M})$ solution concentrations it allowed normal germination rates and increased radicle elongation rates of A. lappacea. The polymer may have potential for use in the restoration of contaminated land by reducing soil solution concentrations of metal cations, and improving plant germination rates through a combination of reduced toxicity and increased soil-water availability. Future research will address whether the particles are as effective in binding to heavy metals in contaminated substrata, increasing the volume of soil solution water available to plants and improving plant establishment.
\end{abstract}




\section{Introduction}

Elevated levels of heavy metals within landscapes, such as cadmium $(\mathrm{Cd})$, copper $(\mathrm{Cu})$, mercury $(\mathrm{Hg})$, manganese $(\mathrm{Mn})$, lead $(\mathrm{Pb})$, nickel $(\mathrm{Ni})$, zinc $(\mathrm{Zn})$, cobalt $(\mathrm{Co})$, uranium $(\mathrm{U})$ and the metalloid arsenic (As) are often a consequence of mining and other industrial activities. More than 110,000 former mining, urban and industrial sites in Australia contain elevated levels of heavy metals (CSIRO, 2004a). Over A $\$ 5$ billion would be required to decontaminate them all. Fewer than $5 \%$ of these contaminated sites have been cleanedup using bioremediation or other methods (Naidu et al., 2003; CSIRO, 2004a). Sites contaminated with heavy metals are frequently problematic for the establishment of vegetation and thus can be prone to erosion and contaminant dispersion into adjacent areas. Many approaches have been used to address heavy metal contamination but none of the current remediation methods are either sustainable, or sufficient to address the risks posed by contaminants (CSIRO, 2004b). For example, one of the most commonly used soil remediation methods, excavation to landfill, is drastic, environmentally disruptive, and can involve substantial costs. It is no longer an acceptable method, especially in the case of extensive contaminated sites (CSIRO, 2004b). The risk of contaminating soils, the food chain, drinking water and air poses threats to ecosystem and human health. It is recognised that exposure to these elements, among others, at elevated bioavailable concentrations can contribute to cancers and degenerative diseases (Lasat, 2000; Tu et al., 2000; Dahmani-Muller et al., 2001; Khan, 2001; Qiao and Luo, 2001; McGrath et al., 2002; Wu et al., 2004).

Metallophytes are plant species tolerant to high available concentrations of heavy metals in the soil, and include species that may have either relatively low or high concentrations of metals in the shoots as compared with the soil (Baker, 1987; Baker et al., 1994). Initial rehabilitation of phytotoxic soils with metallophytes is one means of stabilising metal contaminated sites, but is not always effective because bioavailable concentrations of contaminants in the surface soils may exceed the toxicity thresholds of the selected species, preventing their establishment and growth (Mendez and Maier, 2008a, 2008b), and adequate root formation (Cooke and Johnson, 2002). Reductions in maximum germination percentages and shoot and root length are the most common symptoms of metal toxicity in germinating seeds (Xiong, 1998). Reduced root extension is commonly the first visible symptom (Paschke et al., 2000), and this compromises plant establishment. On this basis, root length (root tolerance index, RTI) is considered to be the most effective indicator of metal tolerance during germination. To establish a persistent plant cover, heavily contaminated sites may require substrate amelioration prior to planting in order to ensure adequate germination and establishment rates (Cooke and Johnson, 2002).

A wide variety of hydrogels has been used to ameliorate arid conditions (Johnson, 1984; Callaghan et al., 1988; Johnson and Leah, 1990; Woodhouse and Johnson, 1991; Rowe et al., 2005) and saline or metalcontaminated soils (El Sayed et al., 1991; Chen et al., 2004; Booth, 2005) due to their ability to provide a temporary source of water during germination and seedling establishment, and to dilute soil ion concentrations to tolerable levels (Guiwei et al., 2008). Nanotechnology offers another approach to metal remediation, through the design of micron/nano-scaled metal-binding polymer particles with very high specific surface area (Fryxell and Mattidod, 2006) and high reactivity (Giammar et al., 2007) that have the capacity to selectively and irreversibly complex metal ions in soil and water (Bell et al., 2006), thus reducing their availability for plant uptake. By combining the two concepts, i.e. synthesising a hydrogel polymer with the capacity to sequester excess cations and increase the volume of plant available water in soil, the prospects for vegetation establishment can be improved. Acrylamide is an ideal material for the synthesis of cross-linked hydrogel particles for use in environmental technologies. These hydrogels exhibit a high water retaining capacity (greater than $90 \%$ of their wet mass), good mechanical strength and resistance to microbial attack (Seybold, 1994). Their degradation is very slow (about 10\% per year) and occurs mainly through physical breakdown (Barvenik, 1994; Seybold, 1994). In addition, these polymers have been shown to pose no environmental threat, (although a lack of inhibitory effects on soil organisms through indirect means or degradation products has not been definitively demonstrated) and their synthesis is relatively cheap so they could be used for large-scale in situ remediation of contaminated soils (Seybold, 1994).

There are many thousand metallophyte plant species, including 14 metal hyper-accumulating plants in Australia, (Pudmenzky et al., 2009) that might be considered for planting on contaminated soils in combination with metal-binding particles. Australian legislation prohibits the import and use of alien plant species, but fortunately Australia has an extremely high endemic plant diversity (Williams et al., 1994; 
Myers et al., 2000), including metallophytes (Reeves, 2003), upon which to base restoration (Baker and Whiting, 2008). Tolerant native species are preferred for the following reasons:

- They possess survival mechanisms appropriate to the local climate, including the arid and semi-arid environments of Australia, and are tolerant to drought, chloride salinity and low soil fertility (Mendez and Maier, 2008a).

- They avoid the introduction of non-native and potentially invasive species that may lead to decreased regional plant biodiversity (Hobbs and Huenneke, 1992; Keeling and Werren, 2005).

- Grasses can achieve relatively rapid ground coverage to stabilise tailings/soils (Bradshaw, 1952; Gadgill, 1969; Williams and Currey, 2002).

- Shrubs and trees offer a broad canopy cover to attenuate erosive forces and establish more extensive and deeper root systems that prevent erosion over the long-term (Belsky et al., 1989; Tiedemann and Klemmedson, 2004).

The objectives of this study were to:

- Assess the $\mathrm{Cu}, \mathrm{Zn}, \mathrm{As}$ and $\mathrm{Pb}$-binding efficiencies of synthesised hydrogel particles in vitro.

- Determine particle water holding capacities in deionised water.

- Assess the effect of particle treatment on in vitro germination percentages, and RTIs of germinating seeds, in an Australian metallophyte grass Astrebla lappacea Lindl. under phytotoxic concentrations of $\mathrm{Zn}$ and $\mathrm{Pb}$.

\section{$2 \quad$ Methodology}

\subsection{Synthesis of cross-linked acrylamide polymers}

Four proprietary cross-linked acrylamide polymers of varying particle size and functionality (Table 1) (micron-size non-functional X1; micron-size xanthate functional X2; micron-size thiol functional X3; and nano-size PDMA-RAFT-trithiocarbamate functional $\mathrm{X} 4$ particles) were synthesised based on the previous work of Bell et al. (2006) and Lord et al. (2003). Surface functionality, and metal-binding moieties of X2, X3 and X4 particles, were introduced by the addition of a reversible addition-fragmentation chain transfer (RAFT). The RAFT-mediating species employed for the synthesis of the X2 and X3 particles was the OEthylxanthyl ethyl benzene (xanthate) and the macromeric RAFT agent P (DMA)-RAFT-trithiocarbamate for X4 particles. The advantage of using the xanthate group is that it binds irreversibly to heavy metal ions and can easily be transformed into thiol groups by facile treatment with hexylamine (Bell et al., 2006). Thiol groups are also well known for their irreversible binding to most heavy metals. The mean hydrodynamic diameters of the particles were determined via dynamic light scattering, and ranged from 10-500 $\mu \mathrm{m}$ for X1, $\mathrm{X} 2$ and $\mathrm{X} 3$ polymers, and it was $238 \mathrm{~nm}$ for $\mathrm{X} 4$ particles.

Table 1 Summary of components and selected properties of particles developed for metal-binding

\begin{tabular}{llll}
\hline $\begin{array}{l}\text { Polymer } \\
\text { Identifier }\end{array}$ & Material & $\begin{array}{l}\text { Surface } \\
\text { Functionality }\end{array}$ & $\begin{array}{l}\text { Mean Particle } \\
\text { Diameter }\end{array}$ \\
\hline X1 & $\begin{array}{l}\text { Cross-linked } \\
\text { acrylamide }\end{array}$ & Non-functional & $10-500 \mu \mathrm{m}$ \\
X2 & $\begin{array}{l}\text { Cross-linked } \\
\text { acrylamide }\end{array}$ & Xanthate functional & $10-500 \mu \mathrm{m}$ \\
X3 & $\begin{array}{l}\text { Cross-linked } \\
\text { acrylamide }\end{array}$ & Thiol functional & $10-500 \mu \mathrm{m}$ \\
X4 & $\begin{array}{l}\text { Cross-linked } \\
\text { acrylamide }\end{array}$ & $\begin{array}{l}\text { trithiocarbamate } \\
\text { functional }\end{array}$ & $238 \mathrm{~nm}$ \\
\hline
\end{tabular}




\subsection{Determination of metal-binding capacities of particles via mixing experiments}

Mixing experiments were conducted to test the capacity of a known mass of X1, X2, X3 and X4 particles to sequester $\mathrm{As}, \mathrm{Cu}, \mathrm{Pb}$ and $\mathrm{Zn}$ from a single solution of each. The initial metal concentrations were selected from previous experiments (data not shown) to represent toxicity thresholds for A. lappacea and included: As, $667 \mu \mathrm{M}$; $\mathrm{Cu}, 4,000 \mu \mathrm{M} ; \mathrm{Pb}, 9,650 \mu \mathrm{M}$ and $\mathrm{Zn}, 10,000 \mu \mathrm{M}$. As $\left(\mathrm{Na}_{2} \mathrm{HAsO}_{4} \cdot 7 \mathrm{H}_{2} \mathrm{O}\right)$ was purchased from Sigma-Aldrich (Germany), $\mathrm{Cu}\left(\mathrm{CuCl}_{2} \cdot 2 \mathrm{H}_{2} \mathrm{O}\right)$ and $\mathrm{Zn}\left(\mathrm{ZnCl}_{2}\right)$ from Chem-Supply Pty Ltd (South Australia, Australia) and $\mathrm{Pb}\left(\mathrm{PbCl}_{2}\right)$ from Lomb Scientific (Coopers Plains, Queensland, Australia). Metal ion solutions were freshly prepared in sterilised deionised water (SDIW). All glassware was acid-washed before use in a dilute (aq) solution of nitric acid and rinsed thoroughly in SDIW. The weight of particles required for the mixing experiments was calculated by using a 1:2 molar ratio of functionality (RAFT group or thiol) to metal for $\mathrm{Cu}, \mathrm{Zn}$ and $\mathrm{Pb}$, and 1:2 and 10.2:1 for As. Metal solution $(10 \mathrm{~mL})$ with or without particles was added into a $20 \mathrm{~mL}$ glass vial and gently shaken over night (12 hours). The experiment was replicated three times. Solutions were then transferred to $15 \mathrm{~mL}$ falcon tubes and centrifuged $\left(3,000 \mathrm{rpm}\right.$ for $30 \mathrm{~min}$ at $\left.22^{\circ} \mathrm{C}\right)$. The supernatant fraction, which contained the free metal ions (the particle pellet fraction contained the bound metals), was carefully pipetted into $10 \mathrm{~mL}$ inductively coupled plasma optical emission spectroscopy (ICPOES) sample tubes. To digest the sample, $25 \mu \mathrm{L}$ of nitric acid (70\%) was added per $1 \mathrm{~mL}$ of supernatant with stirring. The samples were then stored at $4^{\circ} \mathrm{C}$ until analysis of total metal concentrations in solution via ICP-OES against standards. The $\mathrm{r}^{2}$ for all calibration curves was 0.9999. Particle metal-binding efficiencies were calculated by the percentage difference between the total soluble concentrations of metals in the initial solution prior to treatment with particles and after the action of the particles as follows:

$$
\% \text { metal adsorption }=\frac{\left[\begin{array}{c}
\text { Metal concentration in } \\
\text { solution without particles }
\end{array}\right]\left[\begin{array}{l}
\text { Metal concentration in } \\
\text { solution with particles }
\end{array}\right]}{\left[\begin{array}{c}
\text { Metal concentration in } \\
\text { solution without particles }
\end{array}\right]} \times 100
$$

It is recognised that some metal ion binding may have occurred to the glass tubes used for the mixing experiment. However, based on the high metal concentrations used in solution this is considered to be insignificant in terms of the differences between control and treatment solutions.

\subsection{Determination of deionised water holding capacities of particles}

Known amounts of vacuum dried X1, X2, X3 and X4 polymers were placed into tared small glass vials and hydrated with excess deionised water for 12 hours. Three replicates of each polymer were weighed before and after hydration (each polymer type was blotted onto filter paper to remove surplus water before reweighing). Hydrated polymers were allowed to air dry for 48 hours, then dried to constant weight under vacuum at $25^{\circ} \mathrm{C}$ for 24 hours, and re-weighed to obtain the dry weight of the particles. The deionised water holding capacity (DWHC) was calculated as the difference between the hydrated $\left(\mathrm{W}_{\mathrm{h}}\right)$ and dry $\left(\mathrm{W}_{\mathrm{d}}\right)$ polymer weights, expressed as a percentage of polymer dry weight as follows:

$$
\mathrm{DWHC}(\% \mathrm{DW})=\frac{\mathrm{Wh}_{\mathrm{h}}-\mathrm{W}_{\mathrm{d}}}{\mathrm{W}_{\mathrm{d}}} \times 100
$$

\subsection{Effect of polymer treatment on germination percentages and root tolerance indices of Astrebla lappacea seeds}

Seeds of the metallophyte grass A. lappacea were obtained from AustraHort (Queensland, Australia). They had been hand collected from Northern Western Plains, New South Wales (Australia), and stored at $21^{\circ} \mathrm{C}$ for more than 12 months for post-harvest ripening and to break dormancy. The effects of $\mathrm{Zn}(10,000 \mu \mathrm{M}$ in SDIW) and $\mathrm{Pb}(9,650$ and $4,825 \mu \mathrm{M}$ in SDIW) on the germination of A. lappacea seeds were evaluated in the presence, or absence, of micron-size thiol functional X3 polymer. Seeds were surface-sterilised in $20 \%$ sodium hypochlorite for $10 \mathrm{~min}$, rinsed three times in SDIW for $1 \mathrm{~min}$, and placed in disposable plastic Petri dishes $(9 \mathrm{~cm})$ containing two autoclaved $\left(15 \mathrm{~min}, 121^{\circ} \mathrm{C}\right.$, Tomy ES-315 Autoclave, Tokyo, Japan) $84 \mathrm{~mm}$ filter paper discs (Advantec) containing $0.1 \%$ ash and the polyvalent cation polyamide-Epichlorohydrin resin (PAE) as wet-strength agent. Ten $\mathrm{mL}$ of metal solution was added to each treatment Petri dish and SDIW was used for the control treatment. For particle treatment, X3 particles were added to the top filter paper prior to adding the metal solution or SDIW, and the amount of $\mathrm{X} 3$ particles applied was calculated by using a 
1:2 molar ratio of xanthate to metal. The particles were suspended in $50 \mathrm{~mL}$ deionised water and evenly distributed onto the filter paper through filtration using a Buchner funnel. The filter paper manipulated with the X3 polymer was placed on top to ensure contact with the seeds. Twenty-five seeds were placed in each Petri dish and the experiment was replicated five times. The Petri dishes were closed, sealed with Parafilm and placed in a transparent plastic zip resealable bag to minimise water loss. They were then incubated in a controlled temperature cabinet at day and night temperatures of $30^{\circ} \mathrm{C}$ and $25^{\circ} \mathrm{C}$ respectively, with $12: 12$ hours white light and dark conditions. Where necessary, small amounts $(<1 \mathrm{~mL})$ of SDIW were added to Petri dishes to ensure that the position of the air-water interface in the filter paper remained constant and the seeds were in contact with solution but not flooded. Germinated seeds were counted and removed daily, within a laminar flow cabinet (AES Environmental, CLYDE-APAC and Contamination Control Laboratories, Australia) to minimise fungal and bacterial infection, until a plateau of germination (the maximum germination percentage) was reached (13 days in our experiment). Seeds were considered germinated when $2 \mathrm{~mm}$ of radicle had emerged. Radicle lengths were measured from the root-shoot junction to the tip of the longest root on day two and expressed as RTI using the following formula:

$$
\mathrm{RTI}=\frac{\text { Length of the longest radicle in treatment }}{\text { Length of the longest radicle in control }} \times 100
$$

where:

Control $=$ either deionised water alone or deionised water with $\mathrm{X} 3$ particles as appropriate.

Data were tested for significant differences between treatments using one-way analysis of variance (ANOVA, $P<0.05$ ) and mean separation performed using the Tukey's multiple comparison test and 95\% confidence interval $(P<0.05)$ (Matlab ${ }^{\circledR}$ Statistics Toolbox, version 2007b, The Mathworks, USA).

\section{Results and discussion}

\subsection{Metal-binding capacities of the particles}

The micron-size thiol functional cross-linked polymer (X3) was the most efficient at adsorbing metals and reduced the initial solution concentrations of $\mathrm{Pb}^{2+}(9,650 \mu \mathrm{M}), \mathrm{Cu}^{2+}(4,000 \mu \mathrm{M})$ and $\mathrm{Zn}^{2+}(10,000 \mu \mathrm{M})$ by $86.5,75.5$ and $63.8 \%$ respectively (Table 2 ).

Table 2 Percentage reduction (-) or increase $(+)$ in solution metal concentrations by particles is given as the mean \pm standard error $(\mathrm{SE})$ for supernatants $(\mathrm{N}=3)$; nt is not tested

\begin{tabular}{llllll}
\hline $\begin{array}{l}\text { Molar Ratio } \\
\text { RAFT to } \\
\text { Metal }\end{array}$ & $\begin{array}{l}\text { Particle } \\
\text { Type }\end{array}$ & \multicolumn{4}{l}{ Change in Metal Solution Concentration (\%) } \\
\cline { 3 - 6 } & & $\begin{array}{l}\mathbf{A s}^{\mathbf{2}} \\
\mathbf{( 6 6 7} \boldsymbol{\mu M})\end{array}$ & $\mathbf{C} \mathbf{C u}^{\mathbf{2 +}}$ & $\mathbf{P b}^{\mathbf{2 +}}$ & $\mathbf{Z n}^{\mathbf{2 +}}$ \\
\hline- & $\mathrm{X} 1$ & $+3.2 \pm 1.9$ & $-25.1 \pm 2.2$ & $-49.0 \pm 1.0$ & $-23.7 \pm 1.7$ \\
$1: 2$ & $\mathrm{X} 2$ & $+1.5 \pm 2.4$ & $-27.1 \pm 1.1$ & $-43.9 \pm 2.4$ & $-29.2 \pm 3.0$ \\
$1: 2$ & $\mathrm{X} 3$ & $+13.0 \pm 0.7$ & $-75.5 \pm 0.7$ & $-86.4 \pm 0.5$ & $-63.8 \pm 0.7$ \\
$1: 2$ & $\mathrm{X} 4$ & $\mathrm{nt}$ & $-71.8 \pm 3.2$ & $\mathrm{nt}$ & $\mathrm{nt}$ \\
$10.2: 1$ & $\mathrm{X} 2$ & $+66.4 \pm 1.2$ & $\mathrm{nt}$ & $\mathrm{nt}$ & $\mathrm{nt}$ \\
\hline
\end{tabular}

Reducing the size of the RAFT particles from micron- (X2) to nano-size (X4) resulted in an increase of the percentage of $\mathrm{Cu}^{2+}$ sequestration from $27.1-71.8 \%$ (Table 2). This suggests that the high metal-binding efficiencies of $\mathrm{X} 3$ could be improved by reducing its size to nanometer size range.

Arsenic was not adsorbed by any of the particle types tested, and its concentration in the supernatant solution increased by $66.4 \%$ using X2 with a molar ratio of xanthate to As of 10.2:1. This confirms that the particles tested here cannot bind to As anions. On the contrary, we speculate that the $\mathrm{As}^{2-}$ was excluded from the polymer network but water was still taken up and effectively 'removed' which reduced the volume of the 
supernatant and resulted in the same number of moles of As occurring in a reduced volume of supernatant, effectively increasing the As concentration in the supernatant.

\subsection{Deionised water holding capacities of the particles}

The deionised water holding capacities of particles X1, X2, X3 and X4 were tested to investigate the potential of the polymers to provide a water source for seed imbibition and germination. All particles tested in this study exhibited a high water holding capacity from $470.5-1,058.7 \%$ of their dry mass (Table 3 ), suggesting that they have the potential to improve plant water relations under drought conditions by slowly releasing water to the roots. However, the presence of impurities in water, and increasing osmotic potentials, would be expected to decrease water-holding capacity below that obtained for the deionised water used in this experiment. This remains to be assessed.

Table 3 Deionised water holding capacity of particle types as a percentage of dry weight. Data are presented as the mean \pm standard error $(\mathrm{SE})(\mathrm{N}=3)$

\begin{tabular}{ll}
\hline Particle Type & Water Holding Capacity (\%) \\
\hline X1 & $470.5 \pm 38.9$ \\
X2 & $764.1 \pm 16.8$ \\
X3 & $607.8 \pm 30.1$ \\
X4 & $1,058.7 \pm 143.0$ \\
\hline
\end{tabular}

\subsection{Effect of X3 particles on metal bioavailability and seed germination}

The potential for the $\mathrm{X} 3$ particles to bind heavy metals and thus reduce bioavailable concentrations were also tested in vitro in a germination experiment. The germination potential of the metallophyte $A$. lappacea, a tussock-forming perennial grass native to Australia which possesses a robust root system able to stabilise the soil surface, was assessed at heavy metal concentrations known to be phytotoxic to A. lappacea germination in the presence or absence of X3 particles. Different concentrations of $\mathrm{Pb}\left(\mathrm{PbCl}_{2}\right)$ and $\mathrm{Zn}\left(\mathrm{ZnCl}_{2}\right)$ solutions were used, but for brevity, results using phytotoxic concentrations of $\mathrm{Pb}(9,650$ and $4,825 \mu \mathrm{M})$ and $\mathrm{Zn}$ $(10,000 \mu \mathrm{M})$ only, chosen for the mixing experiments in Table 2 and identified from previous experiments (data not shown), are presented in this paper. Maximum germination percentage after 13 days was reduced from $78.4 \%$ in the deionised water control to $8.8 \%$ in the presence of $\mathrm{Pb}$ at $4,825 \mu \mathrm{M}$, which is above the maximum concentration of lead reported for a range of contaminated soils investigated from various countries by Wiersma et al. (1986), and totally inhibited ( $0 \%$ germination) with $\mathrm{Pb}$ at 9,650 $\mu \mathrm{M}$ (Table 4). When X3 particles were added, germination of seeds in the presence of $\mathrm{Pb}$ increased significantly and maximum germination percentages recorded were half to three-quarters of those in the $\mathrm{X} 3$ + deionised water control (94.4\%) for $\mathrm{Pb} 4,825 \mu \mathrm{M}(72.0 \%)$ and $\mathrm{Pb} 9,650 \mu \mathrm{M}(51.2 \%)$, and not significantly different $(\mathrm{p}>0.05)$ from the deionised water control (78.4\%) (Table 4). The addition of particles in the absence of metals increased the maximum germination percentage to $94.4 \%$ (Table 4 ) and also accelerated germination (data not shown). These germination responses show that addition of particles did not cause toxicity to imbibing or germinating seeds and reduced solution concentrations of $\mathrm{Pb}$, which in turn allowed the seeds to germinate in the presence of $\mathrm{Pb}$ concentrations that are normally toxic to this grass species. Similar results were found with $\mathrm{Zn}$ (Table 4). In the presence of 10,000 $\mu \mathrm{M} \mathrm{Zn}$ and X3 particles, the maximum germination percentage $(76 \%)$ was three-quarters that of the control $(94.4 \%)$. In the absence of X3 particles, this concentration of $\mathrm{Zn}$ dramatically decreased the maximum germination percentage from $78.4 \%$ in the control to $4.8 \%$. 
Table 4 Maximum germination percentage (max germ \%) and RTI of Astrebla lappacea in the presence of lead or zinc with or without addition of micron-size thiol functional X3 particles. Results are given as the mean \pm standard error (SE) for $\mathbf{N}=5$. For each attribute, values followed by the same letter were not significantly different $(P>0.05)$

\begin{tabular}{lccc}
\hline Treatment & Max Germ (\%) & \multicolumn{2}{c}{ RTI (\%) } \\
\cline { 2 - 4 } & & Control = Deionised water & Control = Deionised water + X3 \\
\hline Deionised water & $78.4 \pm 2.0^{\mathrm{a}}$ & $100 \pm 0.0^{\mathrm{a}}$ & - \\
Deionised water $+\mathrm{X} 3$ & $94.4 \pm 3.9^{\mathrm{c}}$ & $96.5 \pm 2.7^{\mathrm{a}}$ & $100 \pm 0.0^{\mathrm{a}}$ \\
$\mathrm{Pb}(9,650 \mu \mathrm{M})$ & $0.0 \pm 0.0^{\mathrm{b}}$ & $0.0 \pm 0.0^{\mathrm{b}}$ & - \\
$\mathrm{Pb}(9,650 \mu \mathrm{M})+\mathrm{X} 3$ & $51.2 \pm 9.7^{\mathrm{a}}$ & - & $29.3 \pm 3.3^{\mathrm{b}}$ \\
$\mathrm{Pb}(4,825 \mu \mathrm{M})$ & $8.8 \pm 3.8^{\mathrm{b}}$ & $15.5 \pm 9.8^{\mathrm{b}}$ & - \\
$\mathrm{Pb}(4,825 \mu \mathrm{M})+\mathrm{X} 3$ & $72.0 \pm 4.3^{\mathrm{a}}$ & - & $54.5 \pm 5.6^{\mathrm{b}}$ \\
$\mathrm{Zn}(10,000 \mu \mathrm{M})$ & $4.8 \pm 1.9^{\mathrm{b}}$ & $0.0 \pm 0.0^{\mathrm{b}}$ & - \\
$\mathrm{Zn}(10,000 \mu \mathrm{M})+\mathrm{X} 3$ & $76.0 \pm 5.2^{\mathrm{a}}$ & - & $71.5 \pm 7.6^{\mathrm{b}}$ \\
\hline
\end{tabular}

RTI was used here as an indicator of the alleviation of heavy metal toxicity by particle addition. RTI was calculated after two days of treatment and expressed as a percentage of the maximum radicle length produced in the appropriate control (Equation (3) and Table 4). Radicle elongation was totally inhibited in seeds treated with heavy metals in the absence of X3 particles (RTI $=0 \%$, Table 4$)$ with the exception of $\mathrm{Pb} 4,825 \mu \mathrm{M}(\mathrm{RTI}=15.5 \pm 9.8)$. The large standard error in this treatment was caused by the variable radicle extension with three of the five replicates not producing a radicle. Addition of particles did not affect radicle elongation as RTI of seeds germinated with deionised water in the presence of particles $(96.5 \%)$ was statistically similar $(P>0.05)$ to the deionised water control $(100 \%)$. When particles were added to the metal solution, RTI increased to $29.3 \%, 54.5 \%$ and $71.5 \%$ for $\mathrm{Pb} 9,650 \mu \mathrm{M}, \mathrm{Pb} 4,825 \mu \mathrm{M}$ and $\mathrm{Zn} 10,000 \mu \mathrm{M}$ respectively (Table 4). This demonstrates that RTI of seeds germinated with $\mathrm{Pb}$ and $\mathrm{Zn}$ could be improved by using micron-sized thiol particles and/or increasing the molar ratio of xanthate to metals.

\section{Conclusions}

In summary, our study shows that a micron-size thiol functional cross-linked acrylamide polymer (X3) improves germination percentages of A. lappacea in the presence of $\mathrm{Pb}$ and $\mathrm{Zn}$, and increases the RTI indirectly through reducing metal ion concentrations in solution. If the X3 particles can maintain metal concentrations in the soil solution below the plant toxicity threshold, vegetation could be established on contaminated sites. In addition, the water-holding properties of X3 polymers may contribute to vegetation performance by increasing water supply to plants. Future research relates to whether the X3 particles are effective in binding to heavy metals in contaminated soils or tailings, with a particular focus on stability and durability of the binding. The question of potential toxicity of the particles to soil microfauna and microorganisms will also be addressed, as well as the impact on the soil community of a persistent increase in soil moisture content.

\section{Acknowledgements}

This study was supported by the Centre for Mined Land Rehabilitation and the Australian Institute for Bioengineering and Nanotechnology at The University of Queensland, Australia. The comments of the anonymous reviewers are gratefully acknowledged. 


\section{References}

Baker, A.J.M. (1987) Metal tolerance, New Phytologist, Vol. 106, pp. 93-111.

Baker, A.J.M., McGrath, S.P., Sidoli, C.M.D. and Reeves, R.D. (1994) The possibility of in situ heavy metal decontamination of polluted soils using crops of metal-accumulating plants, Resources, Conservation and Recycling, Vol. 11, pp. 41-49.

Baker, A.J.M. and Whiting, S.N. (2008) Metallophytes - A unique biodiversity and biotechnological resource in the care of the minerals industry, In Proceedings of the Third International Seminar on Mine Closure, A.B. Fourie, M. Tibbett, I.M. Weiersbye, P. Dye (eds), 14-17 October 2008, Johannesburg, South Africa, Australian Centre for Geomechanics, Perth, pp. 13-20.

Barvenik, F.W. (1994) Polyacrylamide characteristics related to soil applications, Soil Science, Vol. 158, pp. 235-243.

Bell, C.A., Smith, S.V., Whittaker, M.R., Whittaker, A.K., Gahan, L.R. and Monteiro, M.J. (2006) Surfacefunctionalized polymer nanoparticles for selective sequestering of heavy metals, Advanced Materials, Vol. 18, pp. 582-586.

Belsky, A.J., Amundson, R.G., Duxbury, J.M., Riha, S.J., Ali, A.R. and Mwonga, S.M. (1989) The effects of trees on their physical, chemical and biological environments in a semi-arid savanna in Kenya, The Journal of Applied Ecology, Vol. 26, pp. 1005-1024.

Booth, D.T. (2005) Establishing Wyoming big sagebrush seed orchards on reclaimed mined land, NATIVE Plants Journal, Vol. 6.3, pp. 247-254.

Bradshaw, A.D. (1952) Populations of Agrostis tenuis resistant to lead and zinc poisoning, Nature, Vol. 169, p. 1098.

Callaghan, T.V., Abdelnour, H. and Lindley, D.K. (1988) The environmental crisis in the Sudan: the effect of waterabsorbing synthetic polymers on tree germination and early survival, Journal of Arid Environments, Vol. 14, pp. 301-317.

Chen, S., Zommorodi, M., Fritz, E., Wang, S. and Huttermann, A. (2004) Hydrogel modified uptake of salt ions and calcium in Populus euphratica under saline conditions, Trees, Vol. 18, pp. 175-183.

Cooke, J.A. and Johnson, M.S. (2002) Ecological restoration of land with particular reference to the mining of metals and industrial minerals: A review of theory and practice, Environmental Reviews, Vol. 10, pp. 41-71.

CSIRO (2004a) CSIRO Sustainability Network, Network letter 46E, Australia, 24 p., viewed 28 June 2009, http://www.bml.csiro.au/susnetnl/netwl46E.pdf.

CSIRO (2004b) Assessment and remediation of contaminated environments, CSIRO, 2 p., viewed 28 June 2009, http://www.clw.csiro.au/publications/general2004/Assessment_Remediation_brochure.pdf.

Dahmani-Muller, H., Van Oort, F. and Balabane, M. (2001) Metal extraction by Arabidopsis halleri grown on an unpolluted soil amended with various metal-bearing solids: a pot experiment, Environmental Pollution, Vol. 114, pp. 77-84.

El Sayed, H., Kirkwood, R.C. and Graham, N.B. (1991) The effects of a hydrogel polymer on the growth of certain horticultural crops under saline conditions, Journal of Experimental Botany, Vol. 41, pp. 891-899.

Fryxell, G.E. and Mattidod, S.V. (2006) Nanomaterials for environmental remediation, In Nanomaterials - toxicity, health and environmental issues, C.S.S.R. Kumar (ed), Wiley-VCh Verlag GmbH and Co., KGaA, Weinheim, pp. $189-210$.

Gadgill, R.L. (1969) Tolerance of heavy metals and the reclamation of industrial waste, Journal of Applied Ecology, Vol. 6, pp. 247-259.

Giammar, D.E., Maus, C.J. and Xie, L. (2007) Effects of particle size and crystalline phase on lead adsorption to titanium dioxide nanoparticles, Environmental Engineering Science, Vol. 24, pp. 85-95

Guiwei, Q., De Varenne, A. and Cunha-Queda, C. (2008) Remediation of a mine soil with insoluble polyacrylate polymers enhances soil quality and plant growth, Soil Use and Management, Vol. 24, pp. 350-356.

Hobbs, R.J. and Huenneke, L.F. (1992) Disturbance, diversity, and invasion: implications for conservation, Conservation Biology, Vol. 6, pp. 324-337.

Johnson, M.S. (1984) The effects of gel-forming polyacrylamides on moisture storage in sandy soils, Journal of the Science of Food and Agriculture, Vol. 35, pp. 1196-1200.

Johnson, M.S. and Leah, R.T. (1990) Effects of superabsorbent polyacrylamides on efficiency of water use by crop seedlings, Journal of the Science of Food and Agriculture, Vol. 52, pp. 431-434.

Keeling, S.M. and Werren, G. (2005) Phytoremediation: The uptake of metals and metalloids by Rhodes grass grown on metal-contaminated soil, Remediation Journal, Vol. 15, pp. 53-61.

Khan, A.G. (2001) Relationships between chromium biomagnification ratio, accumulation factor, and mycorrhizae in plants growing on tannery effluent-polluted soil, Environment International, Vol. 26, pp. 417-423.

Lasat, M.M. (2000) Phytoextraction of metals from contaminated soil: a review of plant/soil/metal interaction and assessment of pertinent agronomic issues, Journal of Hazardous Substance Research, Vol. 2, pp. 1-23.

Lord, H.T., Quinn, J.F., Angus, S.D., Whittaker, M.R., Stenzel, M.H. and David, T.P. (2003) Microgel stars via reversible addition fragmentation chain transfer (RAFT) polymerisation - a facile route to macroporous 
membranes, honeycomb patterned thin films and inverse opal substrates, Journal of Materials Chemistry, Vol. 13, pp. 2819-2824.

McGrath, S.P., Zhao, F.J. and Lombi, E. (2002) Phytoremediation of metals, metalloids, and radionuclides, Advanced Agronomy, Vol. 75, pp. 1-56.

Mendez, M.O. and Maier, R.M. (2008a) Phytostabilization of mine tailings in arid and semi-arid environments - An emerging remediation technology, Environmental Health Perspectives, Vol. 116, pp. 278-283.

Mendez, M.O. and Maier, R.M. (2008b) Phytostabilization of mine tailings in temperate and arid environments, Reviews in Environmental Science and Biotechnology, Vol. 7, pp. 47-59.

Myers, N., Mittermeier, R.A., Mittermeier, C.G., da Fonseca, G.A.B. and Kent, J. (2000) Biodiversity hotspots for conservation priorities, Nature, Vol. 403, pp. 853-858.

Naidu, R., Oliver, D. and McConnell, S. (2003) Heavy metal phytotoxicity in soils, In Health and Environmental Assessment of Site Contamination, Proceedings of the Fifth National Workshop on the Assessment of Site Contamination, A. Langley, M. Gilbey and B. Kennedy (eds), 13-15 May 2002, Adelaide, Australia, Australian Environmental Protection and Heritage Council (EPHC) incorporating the National Environmental Protection Council (NEPC), Adelaide, pp. 235-241.

Paschke, M.W., Redente, E.F. and Levy, D.B. (2000) Zinc toxicity threshold for important reclamation grass species of the Western United States, Environmental Toxicology and Chemistry, Vol. 19, pp. 2752-2756.

Pudmenzky, A., Rossato, L., Doley, D., Ramirez, C. and Baker, A.J.M. (2009) Development of a metallophyte spatial database covering Australia. In Proceedings of the Fourth International Seminar on Mine Closure, A.B. Fourie, M. Tibbett (eds), September 2009, Perth, Australia, Australian Centre for Geomechanics, Perth, in press.

Qiao, X.L. and Luo, Y.M. (2001) Land application of sewage sludge, Sewage sludge with high copper content, Soils, Vol. 33, pp. 222-224.

Reeves, R.D. (2003) Tropical hyperaccumulators of metals and their potential for phytoextraction, Plant and Soil, Vol. 249, pp. 57-65.

Rowe, E.C., Williamson, J.C., Jones, D.L., Holliman, P. and Healey, J.R. (2005) Initial tree establishment on blocky quarry waste ameliorated with hydrogel or slate processing fines, Journal of Environmental Quality, Vol. 34, pp. 994-1003.

Seybold, C.A. (1994) Polyacrylamide review: soil conditioning and environmental fate, Communications in Soil Science and Plant Analysis, Vol. 25, pp. 2171-2185.

Tiedemann, A.R. and Klemmedson, J.O. (2004) Responses of desert grassland vegetation to mesquite removal and regrowth, Journal of Range Management, Vol. 57, pp. 455-465.

Tu, C., Zheng, C.R. and Chen, H.M. (2000) Current status of the soil plant system in a copper gangue area, Acta Pedologica Sinica, Vol. 37, pp. 284-287.

Wiersma, D., Van Goor, B.J. and Van der Veen, N.G. (1986) Cadmium, lead, mercury and arsenic concentrations in crops and corresponding soils in the Netherlands, Journal of Agricultural and Food Chemistry, Vol. 34, pp. 1067-1074.

Williams, D.J. and Currey, N.A. (2002) Engineering closure of an open pit gold operation in a semi-arid climate, International Journal of Surface Mining, Vol. 16, pp. 270-288.

Williams, P.H., Humphries, C.J. and Gaston, K.J. (1994) Centre of seed-plant diversity: the family way, Proceedings of the Royal Society of London, Biological Sciences, Vol. 256, pp. 67-70.

Woodhouse, J.M. and Johnson, M.S. (1991) The effect of gel-forming polymers on seed germination and establishment, Journal of Arid Environments, Vol. 20, pp. 375-380.

Wu, L.H., Li, H., Luo, Y.M. and Christie, P. (2004) Nutrients can enhance phytoremediation of copper-polluted soil by Indian mustard, Environmental Geochemistry and Health, Vol. 26, pp. 331-335.

Xiong, Z.T. (1998) Lead uptake and effect on seed germination and plant growth in a Pb hyperaccumulator Brassica pekinensis Rupr, Bulletin of Environmental Contamination and Toxicology, Vol. 60, pp. 285-291. 